\title{
SCORE - A Model for the Self-Assessment of Creativity Skills in the Context of Computing Education in K-12
}

\author{
Géssica LEHMKUHL, Christiane GRESSE VON WANGENHEIM, \\ Lúcia Helena MARTINS-PACHECO, Adriano F. BORGATTO, \\ Nathalia DA CRUZ ALVES \\ Department of Informatics and Statistics, Federal University of Santa Catarina \\ Florianópolis/SC, Brazil \\ email: gessica.lehmkuhl@grad.ufsc.br,c.wangenheim@ufsc.br,lucia.pacheco@ufsc.br, \\ adriano.borgatto@ufsc.br,nathalia.alves@posgrad.ufsc.br
}

Received: July 2020

\begin{abstract}
In today's society, creativity plays a key role, emphasizing the importance of its development in K-12 education. Computing education may be an alternative for students to extend their creativity by solving problems and creating computational artifacts. Yet, there is little systematic evidence available to support this claim, also due to the lack of assessment models. This article presents SCORE, a model for the assessment of creativity in the context of computing education in $\mathrm{K}-12$. Based on a mapping study, the model and a self-assessment questionnaire are systematically developed. The evaluation, based on 76 responses from K-12 students, indicates a high internal reliability (Cronbach's alpha $=0.961)$ and confirmed the validity of the instrument suggesting only the exclusion of 3 items that do not seem to be measuring the concept. As such, the model represents a first step aiming at the systematic improvement of teaching creativity as part of computing education.
\end{abstract}

Keywords: creativity, assessment, K-12, computing education.

\section{Introduction}

In our globalized world, creativity plays a key role in all areas and, thus, together with critical thinking and problem-solving, it is considered one of the main 21 st century skills (Voogt and Roblin, 2012). Consequently, creativity also plays an important role in K-12 education. Many curricula around the world, mention creativity explicitly as the desired outcome (P21, 2020; Voogt and Roblin, 2012).

Creativity can be understood and defined in different ways depending on the context (Mellini et al., 2010). It can depend on the culture, the person's knowledge, and idio- 
syncratic skills, so that different communities may have different notions of creativity (Amabile, 1982; Said-Metwaly et al., 2017). From a viewpoint of cognitive psychology (Matlin, 2014), creativity is related to the problem-solving field and is generally defined in terms of the capacity to generate new and useful ideas and solutions that are novel, appropriate, functional, correct, and valuable (Walia, 2019). Guilford (1950) characterizes creativity as:

- Fluency: the ability to generate many ideas, which frees creativity.

- Flexibility: the ability to analyze a situation from a different angle, by combining different places, people, directions, and periods.

- Originality: the ability to generate unique or unusual products.

- Elaboration: the ability to engage details, embellish and complete something creative.

Divergent thinking can be considered a type of creative thinking and, although not being the same, both lead to original ideas and solutions (Runco and Acar, 2012). In the context of 21 st-century skills, Binkley et al. (2011) also consider creativity as being able to create valid new ideas effectively. It involves being open to new ideas, diverse perspectives, and feedback as well as to understand failure as a learning opportunity.

To represent the multifaceted nature of creativity it is often classified into 4P's (Rhodes, 1961): Person, Process, Product and Press, The Person strand involves aspects such as personality, traits, attitudes, etc., and focuses on researching questions related to how to identify a creative person. The Process strand focuses on thinking, motivation, communicating processes related to creating tangible results of the creative process represented by the Product strand. The Press strand is related to whether the environment favors the relationship of people regarding creativity. Any of the P's can be analyzed on its own or together to provide a holistic insight.

Focusing on the assessment of creativity in the context of computing education, we are emphasizing Person aspects, referring to the individual that is performing the creative act. This includes the personality and various traits and attitudes of the creative individual, such as creative self-concept, intrinsic motivation, independence of judgment, as well as the individual's creative potential (Gruszka and Tang, 2017). Including also Process aspects, a creative person is expected to be sensitive to problems, has mental flexibility, thinks divergently, and is able to redefine existing objects and concepts.

There are many ways to integrate the teaching of creativity into K-12 and one alternative is through computing education, which has become important as young people need to learn not only how to use Information Technology, but also to create new computational artifacts (CSTA, 2016). In this way, the teaching of computing covering core concepts, such as algorithms and programming and practices has the potential to provide opportunities to students to extend their creativity by solving problems and creating computational artifacts (Yadav and Cooper, 2017; Romero et al., 2017). Currently, computing education is already part of the K-12 curriculum in several countries as well as through extracurricular initiatives to popularize computing competencies (Webb et al., 2017; Heintz et al., 2016; Hubwieser et al., 2015). Even though, observing the importance of computing education for the development of cognitive skills such as creative thinking (Scherer et al., 2019), there is little evidence confirming its contribution. 
Most assessments carried out concerning the impact on creativity of computing education in K-12 are aimed at analyzing the learning of specific skills, such as programming and/or computational thinking (Grover and Pea, 2013), not evaluating the development of other 21 st-century skills. Specifically, concerning computing education there exist only very few approaches to assess creativity, as by analyzing programming artifacts within the educational context (Bennett et al., 2013; Manske and Hoppe, 2014).

A reason for this lack of assessment may be the complexity of the theoretical characterization of the creativity construct making it difficult to assess. So far there exist several general creativity assessment models, including diverse tests, inventories, the judgment of the products created, etc. (Nakano, 2020). Among these, the Torrance Tests of Creative Thinking (TTCT) (Torrance, 1966) is one of the most well-known tests. It associates the cognitive characteristics proposed by Guilford (1956) with emotional characteristics such as expression of emotion, fantasy, and movement, etc. Other instruments include elements such as divergent thinking, analytical thinking, mental flexibility, associative thinking, tolerance for ambiguity, imagination, and inventive capacity (Nakano, 2020). However, assessment models for this skill focusing on the Person in the context of computing education are nonexistent. And, although Bolden et al. (2019) and Snyder et al. (2019) demonstrate the assessment of creativity in any discipline in K-12, none of them targets specifically computing education.

Therefore, the purpose of this article is to present the development of the SCORE (aSsessing COmputing cREativity) model for the assessment of creativity in computing education settings in K-12 adopting a self-assessment instrument that can be used to measure the impact of teaching computing. The model is evaluated in terms of the reliability and validity of the measurement instrument based on a case study conducted in Brazilian schools. The results of this study represent an initial step in order to provide support for the assessment of the impact of computing education in K-12 aiming at the development of creativity.

\section{Related Work}

As a result of a systematic mapping of the literature, we found only ten models aimed at the assessment of creativity in the educational context as shown in Table 1.

The majority of the models are based on well-founded and accepted research (Torrance and Goff, 1989; Guilford, 1967; Sternberg, 1985). Most models focus on evaluating higher education students, mainly in Computer Science and Engineering courses. Applications of three models were also found in Psychology and Educational Sciences courses. Many other models were found but were excluded for not being inserted in an educational context. Most of the models in an educational context are targeting higher education, with only McKlin et al. (2018) and Soroa et al. (2015) also approaching the high school level. No approach for earlier educational stages has been encountered.

In general, the models vary a lot concerning the factors of creativity they assess pointing out a lack of a standardized way to assess creativity. The most frequently con- 
Table 1

Existing approaches for the assessment questionnaires of creativity in educational contexts

\begin{tabular}{ll}
\hline Reference & Name \\
\hline (Auzmendi et al., 1996) & CT - Abedi-Schumacher Creativity Test \\
(Hass and Burke, 2016) & -- \\
(Kaufman, 2012) & K-DOCS - Kaufman Domains of Creativity Scale \\
(McKlin, et al., 2018) & Student Engagement Survey \\
(Oihus et al., 2013) & TestMyCreativity \\
(Romero et al, 2017) & Assessment Scale of Creative Collaboration \\
(Runco et al., 2001) & RIBS - Runco Ideational Behavior Scale \\
(Shell et al., 2013) & ECCI-i - Epstein Creativity Competencies Inventory for Individuals \\
(Soroa et al., 2015) & EDICOS - Emotion/motivation $\square$ related Divergent and Convergent thinking \\
& styles Scale \\
(Susnea and Vasiliu, 2016) & IACEST - Indirect Assessment of Creativity through the Estimation of \\
& Stereotypical Thinking \\
\hline
\end{tabular}

\footnotetext{
abstraction (1) aesthetic taste and imagination (1) artistic (1) assessment (1) boldness (1) broadens skills and knowledge (1) changes physical and social environment (1) complexity (1) connection (1) convergent-preventive (1) convergent-unpleasant (1) creative personality and thinking style items (1) creative thinking skills (1) curiosity (1) decision skill and flexibility (1) disciplinary (1) divergent-pleasant (1) divergent-proactive (1) drive for accomplishment (1) elaboration (1) everyday (1) exploration (1)

Fig. 1. Creativity factors assessed.

sidered factors are originality, fluency, flexibility, and curiosity (Fig. 1). Yet, considering that there is a global effort to carry out creativity assessments, whether in K-12 or higher education, given the variety of sources and definitions used for the development of the models, there still does not seem to exist an agreement concerning how to evaluate this skill.

Most models use a Likert scale to answer the assessment questionnaire, followed by three models that use an ordinal scale and one model that uses a multiple-choice answer. They also differ considerably in the number of items in the questionnaire, ranging from 18 to 60 items as detailed in Table 2 .

The majority of the models has been systematically developed based on previous work and/or theoretical models. Most models (with only two exceptions (Oihus et al., 2013; Romero et al., 2017)) present in detail the evaluation of the proposed measurement instrument. On the other hand, one study only partially assessed its data collection instrument and two others did not provide the data. Four of the studies analyzed factors such as reliability and validity, while others focused exclusively on reliability. The results of these evaluations are consistent, with most presenting a Cronbach's alpha above 0.70 and three models above 0.90 indicating acceptable to excellent internal consistency of their items (McKlin et al., 2018; Runco et al., 2001; Kaufman, 2012). 
Table 2

Characteristics of the existing assessment questionnaires

\begin{tabular}{lll}
\hline Reference & Quantity of items & Scale type \\
\hline (Auzmendi et al., 1996) & 60 & Multiple choice \\
(Hass and Burke, 2016) & 46 & 4-point Likert scale \\
(Kaufman, 2012) & 50 & 5-point Likert scale \\
(McKlin, et. al., 2018) & 18 & 5-point Likert scale \\
(Oihus et al., 2013) & 31 & 10-point Likert scale, multiple-choice, open questions \\
(Romero et al, 2017) & -- & 5-point ordinal scale \\
(Runco et al., 2001) & 23 & 5-point Likert scale \\
(Shell et al., 2013) & 28 & 5-point ordinal scale \\
(Soroa et al., 2015) & 30 & 6-point Likert scale \\
(Susnea and Vasiliu, 2016) & 20 & 5-point Likert scale
\end{tabular}

Yet, although these results indicate some generic models for assessing creativity, there are still none available in the context of computing education in K-12, especially when focusing on elementary and middle school.

\section{Research Methodology}

To develop the SCORE model, a multi-method research was performed. Initially, we elicited the state of the art identifying existing approaches for self-assessment of creativity in an educational context through a systematic mapping study in accordance to Petersen et al. (2008). Based on the literature review, the SCORE model has been developed following the procedure of the scale development guide proposed by DeVellis (2016) and the guide for questionnaire design by Kasunic (2005).

Adopting the Goal/Question/Metric approach (GQM) (Basili et al., 1994), the assessment objective was defined and systematically decomposed into factors to be measured. The factors were defined to support the development of the measurement instrument (questionnaire), based on a mapping study of their concepts following the procedure proposed by Budgen et al. (2008). The measurement of the factors is operationalized by decomposing the factors into measurement instrument items. The definition of the items is based on other questionnaires found in the literature. We analyzed the pool of items in terms of similarity and redundancy, customizing, and unifying the selected items. To standardize the selected items, all items were refined and transformed into positive statements. The response format for the items of the measurement instrument was determined based on response formats typically used following the scale development guide proposed by DeVellis (2016). Face validity (Trochim and Donnelly, 2018) has been analyzed through an expert panel composed of a multidisciplinary group of senior researchers with backgrounds in computing and/or statistics as well as representatives of the target audience. The review aimed at analyzing clar- 
ity, relevance, consistency, and completeness of the SCORE measurement instrument items. Based on the suggestions of the experts and the young people, changes in the wording and text formatting have been made to improve the preliminary version of the measurement instrument.

Then, to evaluate the SCORE model in terms of reliability and validity concerning its measurement instrument, we conducted a case study following Yin (2009) and Wohlin et al. (2012) applying the self-assessment questionnaire in a one-shot posttest only design (without applying any treatment). We pooled the data collected at each school into a single sample for data analysis. Data were analyzed in terms of reliability and construct validity following the definition of Trochim \& Donnelly (2018) and the scale development guide proposed by DeVellis (2016). In terms of reliability, we measured internal consistency through Cronbach's alpha coefficient (Cronbach, 1951). Construct validity was analyzed using exploratory factor analysis and based on evidence of convergent and discriminant validity, obtained through the degree of correlations of the items (DeVellis, 2016; Trochim and Donnelly, 2018). In addition, a factor analysis was used to determine how many factors underlie the set of items of the SCORE questionnaire, following the analysis process proposed by Brown (2006). The results of the statistical analysis were interpreted by researchers in the context of computing education to identify the reliability and validity of the SCORE measurement instrument, as well as to propose improvements to the SCORE measurement instrument.

\section{Development of the SCORE Model}

The objective of the SCORE (aSsessing COmputing cREativity) model is to evaluate the creativity skills of students in the context of computing education in K-12 from the student's perception. Based on the creativity definition and general assessment models in the literature, we decomposed the abstract concept of creativity into a set of factors as presented in Table 3 .

The target audience is students from elementary to high school. The model can be applied in different ways, depending on the type of study and the research design chosen ranging from non-experimental studies, using one-shot post-test designs with specific applications and/or after the treatment or one-shot pre-test/post-test before and after treatment, as well as in (quasi-) experimental studies, involving control groups.

Aiming at the measurement of the degree of the skills defined in Table 3, a self-assessment questionnaire has been developed as a data collection instrument. We opted for this kind of assessment, as it is quick to administer and easy to score (Kaufman, 2019). Limitations of this type of assessment are associated with the respondents' subjective questions as answers idealized by them as desirable, untrue or exaggerated to appear to be better since many people do not perceive their own creative skills (underestimating or overestimating) or the personal concept of creativity. Yet, the credibility 
Table 3

Definition of the factors of the SCORE model

\begin{tabular}{|c|c|c|}
\hline Factor & Description & Source \\
\hline $\begin{array}{l}\text { Creative } \\
\text { personality and } \\
\text { curiosity }\end{array}$ & $\begin{array}{l}\text { A lifestyle, a personality trait, wanting to see, hear, know, } \\
\text { experience something new, original, unknown. }\end{array}$ & $\begin{array}{l}\text { Susnea and Vasiliu, 2016; } \\
\text { Kaufman, 2012; } \\
\text { Oihus et al., 2013; } \\
\text { Hass and Burke, 2016; }\end{array}$ \\
\hline $\begin{array}{l}\text { Knowledge and } \\
\text { skills expansion }\end{array}$ & $\begin{array}{l}\text { Stimulating creativity means learning new things outside the } \\
\text { current areas of knowledge. It means to have the capacity for } \\
\text { great achievements, including verbal and linguistic creativity. }\end{array}$ & $\begin{array}{l}\text { Shell et al., 2013; } \\
\text { Hass and Burke, 2016; } \\
\text { Kaufman, } 2012\end{array}$ \\
\hline Connection & $\begin{array}{l}\text { To be able to make connections with things that have no apparent } \\
\text { connection. }\end{array}$ & $\begin{array}{l}\text { Oihus et al., 2013; } \\
\text { Hass and Burke, } 2016\end{array}$ \\
\hline Boldness & $\begin{array}{l}\text { To be able to overcome boundaries of accepted conventions and } \\
\text { to not be afraid to make mistakes. }\end{array}$ & $\begin{array}{l}\text { Hass and Burke, 2016; } \\
\text { Oihus } \text { et al., 2013; } \\
\text { Shell et al., } 2013\end{array}$ \\
\hline Originality & To be able to produce unique or unusual ideas. & $\begin{array}{l}\text { Auzmendi et al., 1996; } \\
\text { McKlin et al., 2018; } \\
\text { Runco et al., } 2001\end{array}$ \\
\hline Fluency & $\begin{array}{l}\text { To be able to generate many ideas to evaluate, research, and } \\
\text { choose different solutions to a problem. }\end{array}$ & $\begin{array}{l}\text { Auzmendi et al., 1996; } \\
\text { Runco et al., 2001; } \\
\text { McKlin et al., } 2018\end{array}$ \\
\hline Flexibility & $\begin{array}{l}\text { To be able to produce ideas that show a diversity of possibilities, } \\
\text { through different points of view or domains of thought. }\end{array}$ & $\begin{array}{l}\text { Auzmendi et al., 1996; } \\
\text { Oihus et al., 2013; } \\
\text { McKlin et al., 2018; } \\
\text { Runco et al., } 2001\end{array}$ \\
\hline Elaboration & $\begin{array}{l}\text { To take care of details, beautifying, and completing something } \\
\text { creative to make something real, understandable, or aesthetically } \\
\text { pleasing. }\end{array}$ & Auzmendi et al., 1996 \\
\hline
\end{tabular}

of creativity self-assessment depends on its use and can present a good approximation of consolidated tests based on performance measures (Kaufman, 2019). Likewise, the self-assessment of creativity can estimate how something impacts how a person feels about their creativity and, in many cases, represents the best possible measure when it comes to examining personal beliefs and insights about creativity itself. Thus, although there is no consensus in the literature, there is evidence that self-assessment can produce reliable, valid, and useful data (Ross, 2006), especially when using reliable and valid measurement instruments (Sitzmann et al., 2010). Therefore, as a compromise, we develop a statistically validated measurement instrument, increasing the validity and reliability of the data collected in the self-assessment (DeVellis, 2016; Kasunic, 2005).

The questionnaire items are defined based on the literature. Items related to skills not covered by any of the models found in the literature review are based on complementary references and/or our practical experiences. The items were carefully formulated, taking into account the target audience. As response format, we chose a 4-point Likert scale, typically used for cases in which the respondent should take a position, whatever it may be, regarding the item (Losby and Wetmore, 2012). 
Table 4

Version 1.0 of the SCORE self-assessment questionnaire

\begin{tabular}{lrl}
\hline Factor & ID & Item \\
\hline $\begin{array}{l}\text { Creative } \\
\text { personality } \\
\text { and curiosity }\end{array}$ & $1 \begin{array}{l}\text { Sometimes I keep thinking about } \\
\text { a problem a lot and keep trying to } \\
\text { solve it, until I find a solution, for } \\
\text { example, doing a math exercise. }\end{array}$ \\
$2 \begin{array}{l}\text { I think it's important to have } \\
\text { ideas. }\end{array}$ \\
$3 \begin{array}{l}\text { I have many useful ideas. } \\
4\end{array}$ \\
$\begin{array}{l}\text { I can do something fun with recy- } \\
\text { cled material. } \\
\text { I can think of new ways to help } \\
\text { people. }\end{array}$ \\
$6 \begin{array}{l}\text { I like to do new things (visit new } \\
\text { places, meet new people, etc.) }\end{array}$
\end{tabular}

Source

Creative personality and curiosity

Knowledge and skills expansion

Source


Table 4 - continued from previous page

\begin{tabular}{lll}
\hline Factor & ID Item & Source \\
\hline $16 \quad \begin{array}{l}\text { I know how to enjoy praise and } \\
\text { criticism when redoing a school } \\
\text { assignment. }\end{array}$ & $\begin{array}{l}\text { Figuring outhow to integrate critiques and suggestions } \\
\text { while revising a work (Kaufman, 2012) }\end{array}$ \\
17 I can give constructive criticism. & $\begin{array}{l}\text { Being able to offer constructive feedback based on } \\
\text { my own reading of a paper (Kaufman, 2012) }\end{array}$ \\
18 I learn from my mistakes. & $\begin{array}{l}\text { Ilearn from my mistakes or when my ideas do not work } \\
\text { out (Martins-Pacheco } \text { et al., 2020); I make mistakes, } \\
\text { My mistakes lead me to something new (Petty, 1997); } \\
\text { I accept errors and therefore, I accept my mistakes and } \\
\text { those of others (Romero et al., 2017). }\end{array}$
\end{tabular}

Connection 19 I can discover relationships I can discover different links and relationships between the use of computers and (obvious and not so obvious) when I look at different their impact on society.

information sources; I can find the connection between items (Fields and Bisshof, 2013).

20 I can understand and interpret Has the ability to understand and interpret his or her the type of problem to be solved, own environment (Hass and Burke, 2016)

for example, how to do a math exercise.

21 I can pay attention to and Is able to grasp ideas and focus his or her attention on understand other people's ideas. those ideas (Hass and Burke, 2016)

22 I can create new solutions by Is able to grasp ideas and focus his or her attention on combining things I already know. those ideas; Is able to put old information, theories, and so forth together in a new way (Hass and Burke, 2016); I attain understanding from a variety of information sources without difficulty (Fields and Bisshof, 2013)

Boldness

23 I like to do things the way I want. I enjoy having leeway in the things I do and room to make up my own mind (Runco et al., 2001)

24 I can do anything I want. Tends not to known own limitations (Hass and Burke, 2016)

25 I try to do what others think is Tries to do what others think is impossible (Hass and impossible. Burke, 2016)

26 My goals are always challenging. When I set goals for myself, I make sure they're ambitious and open-ended (Shell et al., 2013)

27 When I encounter a very difficult When you face a very difficult problem, what do problem, I have the courage to try you usually do? When you face a problem that is not to solve it. common, how do you usually solve it? (Auzmendi et al., 1996)

28 I am not afraid of failing.

I am not afraid of failure (Shell et al., 2013); I feel very embarrassed if I fail (inverted scale Susnea and Vasiliu, 2016);

29 I like to participate in challenges. Do you like to solve difficult problems? (Auzmendi et al., 1996)

30 I am not ashamed to talk about I am not ashamed to talk about my ideas (Martinsmy ideas. Pacheco et al., 2020).

Originality $\quad 31$ I like to create my own digital Do you like going to the lab to do experiments? games. (Auzmendi et al., 1996); I want to develop my own game (Petty, 1997)

32 I try to solve a problem on my When you face a class of problems that you are not own before asking someone. used to, what do you do? (Auzmendi et al.,1996) 
Table 4 - continued from previous page

\begin{tabular}{|c|c|c|c|}
\hline Factor & ID & Item & Source \\
\hline & 33 & $\begin{array}{l}\text { I like to create new mobile apps } \\
\text { and not just to use the ones that } \\
\text { already exist. }\end{array}$ & $\begin{array}{l}\text { I can come up with new ways to do things in } \\
\text { computing (McKlin et al., 2018) }\end{array}$ \\
\hline & 34 & $\begin{array}{l}\text { I already did something using the } \\
\text { computer that I never thought was } \\
\text { possible. }\end{array}$ & $\begin{array}{l}\text { I produced something in computing that I never } \\
\text { thought was possible (McKlin et al., 2018) }\end{array}$ \\
\hline & 35 & $\begin{array}{l}\text { I think it is important to think } \\
\text { about things in many different } \\
\text { ways. }\end{array}$ & $\begin{array}{l}\text { It is important to be able to think of bizarre and } \\
\text { wild possibilities (Runco et al., 2001) }\end{array}$ \\
\hline & 36 & $\begin{array}{l}\text { I imagine many things that do not } \\
\text { yet exist. }\end{array}$ & $\begin{array}{l}\text { I invent/imagine a lot of things that not yet exist } \\
\text { (Martins-Pacheco et al., 2020); is imaginative (Hass } \\
\text { and Burke, 2016) }\end{array}$ \\
\hline & 37 & $\begin{array}{l}\text { I like to modify computer pro- } \\
\text { grams from programs that other } \\
\text { people have shared. }\end{array}$ & -- \\
\hline & 38 & $\begin{array}{l}\text { I have ideas on how to make new } \\
\text { games and how to improve them. }\end{array}$ & $\begin{array}{l}\text { I have ideas about new inventions or about how to } \\
\text { improve things (Runco et al., 2001); I am considering } \\
\text { how I can further improve my computer game (Petty, } \\
\text { 1997) }\end{array}$ \\
\hline
\end{tabular}

Fluency

39 I can imagine different solutions Coming up with a new way to think about an old debate to solve a problem (for example, (Kaufman, 2012); Has the ability to change direction how to get to school faster). $\quad$ and use another procedure (Hass and Burke, 2016); I am able to solve a problem in different ways (MartinsPacheco et al., 2020); I can simultaneously propose a variety of solutions to a specific problem (Fields and Bisshof, 2013); I look for different solutions to a computing problem (McKlin et al., 2018)

40 I find it easy to write a story for Can you express your ideas well when you write? a game.

Do you find it easy to write narratives or stories? (Auzmendi et al., 1996); I find it easy to develop a strategy for a project (Rahimi et al., 2011).

41 I can write a computer program. Writing a ten-line poem would be easier for me (Auzmendi et al., 1996)

42 When I grow up, I would like Would you like a job where you often have to think of to work with something that new ideas? (Auzmendi et al., 1996) involves thinking about several new ideas.

43 I can think of a list of things If you were invited to a city hall meeting to discuss that require little money but can problems in your city, would it be difficult to think of improve my school. a list of problems?; Would it be difficult for you to help a school with limited resources to find new and interesting ideas for sports and games? (Auzmendi et al., 1996)

44 I am able to explain a computer If you are with a group of friends and they asked you program to colleagues. to talk to them about your experience for an hour, how do you think you would do that? (Auzmendi et al., 1996)

45 I have ideas for mobile apps that I I am capable of exploring many different ideas, could develop. options, or outcomes in computing. (McKlin et al., 2018); I ask questions regarding the game that I'm developing (Petty, 1997) 
Table 4 - continued from previous page

\begin{tabular}{|c|c|c|c|}
\hline Factor & ID & Item & Source \\
\hline \multirow[t]{5}{*}{ Flexibility } & 46 & $\begin{array}{l}\text { I am able to combine ideas in } \\
\text { ways that other people have not } \\
\text { tried. }\end{array}$ & $\begin{array}{l}\text { I am good at combining ideas in ways that others have } \\
\text { not tried. (Runco et al., 2001); I don't reject ideas } \\
\text { with initial faults but find ways to make them work } \\
\text { (Rahimi et al., 2011) }\end{array}$ \\
\hline & 47 & $\begin{array}{l}\text { I can think of new ways to use a } \\
\text { pan. }\end{array}$ & $\begin{array}{l}\text { Are you able to find different uses for things, that is, } \\
\text { uses that are uncommon for them? (Auzmendi et al., } \\
\text { 1996) }\end{array}$ \\
\hline & 48 & $\begin{array}{l}\text { I like to work on creating new } \\
\text { things instead of doing repetitive } \\
\text { exercises. }\end{array}$ & $\begin{array}{l}\text { I like the kind of work that requires the creation and } \\
\text { use of many new ideas. (Auzmendi et al., 1996) }\end{array}$ \\
\hline & 49 & $\begin{array}{l}\text { I can find the materials I need to } \\
\text { develop an idea. }\end{array}$ & $\begin{array}{l}\text { I am resourceful and can find the materials I need } \\
\text { (Rahimi et al., 2011) }\end{array}$ \\
\hline & 50 & $\begin{array}{l}\text { If a certain resource is not } \\
\text { available, I try to find a solution } \\
\text { with other available resources. }\end{array}$ & $\begin{array}{l}\text { A valuable solution that responds to the situation } \\
\text { constraints. An efficient solution that required a } \\
\text { limited number of resources (Romero et al., 2017) }\end{array}$ \\
\hline \multirow[t]{6}{*}{ Elaboration } & 51 & $\begin{array}{l}\text { I care about the details when I do } \\
\text { something. }\end{array}$ & $\begin{array}{l}\text { How much do you care about details when you do } \\
\text { something? (Auzmendi et al., 1996); I care about } \\
\text { detail and work well done (Romero et al., 2017). }\end{array}$ \\
\hline & 52 & $\begin{array}{l}\text { I pay attention to the colors and } \\
\text { fonts used on the screen of a } \\
\text { mobile application. }\end{array}$ & $\begin{array}{l}\text { When you are interested in something, how much } \\
\text { attention do you pay to details? (Auzmendi et al., } \\
\text { 1996) }\end{array}$ \\
\hline & 53 & $\begin{array}{l}\text { After using an interesting mobile } \\
\text { application, I like to talk to } \\
\text { someone about it. }\end{array}$ & $\begin{array}{l}\text { After watching a movie that impressed me, I think a } \\
\text { lot about what happened in the movie and talk about } \\
\text { it with someone (Auzmendi et al., 1996) }\end{array}$ \\
\hline & 54 & $\begin{array}{l}\text { When I'm interested in something, } \\
\text { I pay attention to every detail. }\end{array}$ & $\begin{array}{l}\text { How concerned are you with details when you do } \\
\text { something?; When you are interested in something, } \\
\text { how much attention do you pay to details? } \\
\text { (Auzmendi et al., 1996); I consider important to } \\
\text { examine the details of a complex problem (Soroa } \\
\text { et al., 2015) }\end{array}$ \\
\hline & 55 & $\begin{array}{l}\text { When I do homework, I like to } \\
\text { make it beautiful and decorated. }\end{array}$ & $\begin{array}{l}\text { Has an appreciation for art, music, and so forth; has } \\
\text { good taste (Hass and Burke, 2016) }\end{array}$ \\
\hline & 56 & $\begin{array}{l}\text { I like to make the screens of } \\
\text { games or mobile applications that } \\
\text { I create beautiful. }\end{array}$ & -- \\
\hline
\end{tabular}

A preliminary version of the questionnaire was reviewed by an expert panel. The multidisciplinary panel was composed of 9 researchers from a background in computing, education, design, and/or microelectronics, and 3 representatives of the target audience (young people aged 11 to 15 years). The participants reviewed each item in the questionnaire for relevance and understanding. The questionnaire was also evaluated in terms of its completeness and consistency. Based on the feedback obtained, several items were changed, especially concerning their formulation, to improve understanding by the target audience, few items were removed, and others were decomposed into separate items for a better representation. As a result, a 56-item questionnaire as presented in Table 4 was defined. 


\section{Evaluation of the SCORE Model}

To evaluate the reliability and validity of the measuring instrument of the SCORE model, we conducted a case study.

\subsection{Definition of the Evaluation}

The purpose of the evaluation has been to evaluate the reliability and validity of the selfassessment questionnaire as a measurement instrument. For this, the following questions are analyzed:

- Is there evidence of internal consistency in the measuring instrument?

- Is there evidence of convergent and discriminant validity in the measuring instrument?

- How do the underlying factors influence the responses of the items of the measuring instrument?

Data were collected from the application of the questionnaire in a case study in K-12 (without the application of any specific treatment). Students answered a version of the questionnaire in Brazilian Portuguese available online only due to the pandemic. The study has been approved by the Ethics Committee of the Federal University of Santa Catarina.

\subsection{Execution of the Evaluation}

The questionnaire was applied from March to April 2020. A total of 76 K-12 students aged 8 to 17 years participated in the research in six schools in the south of Brazil (Table 5).

\subsection{Data Analysis}

\subsubsection{Is there Evidence of Internal Consistency in the Measuring Instrument?}

Internal consistency indicates whether all parts of an instrument measure the same characteristic, which can be analyzed using Cronbach's alpha coefficient (Cronbach, 1951).

Table 5

Overview of the participants in the study

\begin{tabular}{lc}
\hline Educational stagr & Number of psrticipants \\
\hline Elementary school (Year 1-5) & 43 \\
Middle school (Year 6-9) & 26 \\
High school (Year 10-12) & 7 \\
Total & $\mathbf{7 6}$ \\
\hline
\end{tabular}


Table 6

Cronbach's alpha coefficient for each item if excluded

\begin{tabular}{rl}
\hline Item & $\begin{array}{l}\text { Cronbach's alpha, } \\
\text { if item excluded }\end{array}$ \\
\hline $\mathbf{1}$ & 0.960 \\
$\mathbf{2}$ & 0.960 \\
$\mathbf{3}$ & 0.960 \\
$\mathbf{4}$ & 0.960 \\
$\mathbf{5}$ & 0.960 \\
$\mathbf{6}$ & 0.960 \\
$\mathbf{7}$ & 0.960 \\
$\mathbf{8}$ & 0.960 \\
$\mathbf{9}$ & 0.961 \\
$\mathbf{1 0}$ & 0.960 \\
$\mathbf{1 1}$ & 0.960 \\
$\mathbf{1 2}$ & 0.959 \\
$\mathbf{1 3}$ & 0.959 \\
$\mathbf{1 4}$ & 0.960 \\
$\mathbf{1 5}$ & 0.960 \\
$\mathbf{1 6}$ & 0.960 \\
$\mathbf{1 7}$ & 0.960 \\
$\mathbf{1 8}$ & 0.960 \\
$\mathbf{1 9}$ & 0.959 \\
\hline
\end{tabular}

\begin{tabular}{ll}
\hline Item & $\begin{array}{l}\text { Cronbach's alpha, } \\
\text { if item excluded }\end{array}$ \\
\hline $\mathbf{2 0}$ & 0.960 \\
$\mathbf{2 1}$ & 0.959 \\
$\mathbf{2 2}$ & 0.960 \\
$\mathbf{2 3}$ & 0.961 \\
$\mathbf{2 4}$ & 0.961 \\
$\mathbf{2 5}$ & 0.960 \\
$\mathbf{2 6}$ & 0.960 \\
$\mathbf{2 7}$ & 0.960 \\
$\mathbf{2 8}$ & 0.961 \\
$\mathbf{2 9}$ & 0.960 \\
$\mathbf{3 0}$ & 0.961 \\
$\mathbf{3 1}$ & 0.960 \\
$\mathbf{3 2}$ & 0.960 \\
$\mathbf{3 3}$ & 0.960 \\
$\mathbf{3 4}$ & 0.960 \\
$\mathbf{3 5}$ & 0.960 \\
$\mathbf{3 6}$ & 0.960 \\
$\mathbf{3 7}$ & 0.960 \\
$\mathbf{3 8}$ & 0.960
\end{tabular}

\begin{tabular}{ll}
\hline Item & $\begin{array}{l}\text { Cronbach's alpha, } \\
\text { if item excluded }\end{array}$ \\
\hline $\mathbf{3 9}$ & 0.959 \\
$\mathbf{4 0}$ & 0.960 \\
$\mathbf{4 1}$ & 0.960 \\
$\mathbf{4 2}$ & 0.960 \\
$\mathbf{4 3}$ & 0.960 \\
$\mathbf{4 4}$ & 0.960 \\
$\mathbf{4 5}$ & 0.960 \\
$\mathbf{4 6}$ & 0.960 \\
$\mathbf{4 7}$ & 0.960 \\
$\mathbf{4 8}$ & 0.960 \\
$\mathbf{4 9}$ & 0.960 \\
$\mathbf{5 0}$ & 0.960 \\
$\mathbf{5 1}$ & 0.960 \\
$\mathbf{5 2}$ & 0.960 \\
$\mathbf{5 3}$ & 0.960 \\
$\mathbf{5 4}$ & 0.960 \\
$\mathbf{5 5}$ & 0.960 \\
$\mathbf{5 6}$ & 0.960 \\
\end{tabular}

Cronbach's alpha coefficient indicates the degree to which a set of items measures a single factor. Cronbach's alpha values between 0.7 and 0.8 are acceptable, between 0.8 and 0.9 are good, and greater than 0.9 are excellent indicating an internal consistency of the instrument (Cronbach, 1951).

The analysis of the questionnaire's reliability shows a Cronbach's alpha coefficient $\alpha=0.961$, indicating an excellent internal consistency of the items. We also analyzed Cronbach's alpha for each item if excluded, expecting that no item exclusion would cause an increase in Cronbach's alpha (Table 6). These results also show that none of the items affects the internal consistency of the assessment instrument, and, therefore, there is no indication for the exclusion of any of the items.

\subsubsection{Is there Evidence of Convergent and Discriminant Validity?}

To obtain evidence of convergent and discriminant validity of the instrument, the correlations of the items were calculated (DeVellis, 2016). Convergent validity shows whether the items that should be related are related, while discriminant validity, on the other hand, shows whether the items that should not be related are not related.

Therefore, Spearman's nonparametric correlation matrix was used that shows Spearman's correlation coefficient (Daniel, 1990). To perform the analysis of the coefficients, Cohen's coefficient was adopted. A correlation between items is considered satisfactory when the coefficient is greater than 0.29 , which indicates a moderate correlation (marked 
in green). A coefficient above 0.50 indicates a high correlation (marked in blue). A negative coefficient, shown in red, indicates a divergent correlation, which indicates that different factors are being measured (Cohen, 1988).

The items related to the factor "Creative personality and curiosity" present moderate and high correlation as well as one item with a negative correlation. The item "IT9: I question beliefs, customs, and traditions, for example, not passing under the stairs to be unlucky", shows significant correlations only with item IT1 and presents a divergent correlation with items IT2, IT6, and IT8, indicating that it seems to measure another factor. "IT7: I am a curious person about how things work" demonstrates a good correlation with almost all other items, except for "IT5: I can think of new ways to help people" as shown in Table 7.

The items related to the factor "knowledge and skills expansion" show a moderate and high correlation, indicating that they measure the same factor. Some items show a good correlation with all other items, such as item "IT15: I like to discuss subjects giving my opinion". Only item "IT16: I know how to take advantage of praise and criticism when redoing school work", presents a divergent correlation with item IT15, as shown in Table 8.

Table 7

The correlation coefficient of creative personality and curiosity

\begin{tabular}{llllllllll}
\hline & IT1 & IT2 & IT3 & IT4 & IT5 & IT6 & IT7 & IT8 & IT9 \\
\hline IT1 & 1 & & & & & & & & \\
IT2 & 0,268 & 1 & & & & & & & \\
IT3 & 0,267 & 0,545 & 1 & & & & & & \\
IT4 & 0,181 & 0,298 & 0,316 & 1 & & & & & \\
IT5 & 0,314 & 0,224 & 0,221 & 0,400 & 1 & & & & \\
IT6 & 0,137 & 0,265 & 0,299 & 0,090 & 0,187 & 1 & & & \\
IT7 & 0,290 & 0,358 & 0,536 & 0,437 & 0,142 & 0,383 & 1 & & \\
IT8 & 0,134 & 0,514 & 0,159 & 0,345 & 0,210 & 0,257 & 0,359 & 1 & \\
IT9 & 0,306 & $-0,098$ & 0,017 & 0,190 & 0,161 & $-0,056$ & 0,179 & $-0,020$ & 1 \\
\hline
\end{tabular}

Table 8

The correlation coefficient of knowledge and skills expansion

\begin{tabular}{llllllllll}
\hline & IT10 & IT11 & IT12 & IT13 & IT14 & IT15 & IT16 & IT17 & IT18 \\
\hline IT10 & 1 & & & & & & & & \\
IT11 & 0,618 & 1 & & & & & & & \\
IT12 & 0,492 & 0,571 & 1 & & & & & & \\
IT13 & 0,411 & 0,364 & 0,546 & 1 & & & & & \\
IT14 & 0,368 & 0,220 & 0,393 & 0,431 & 1 & & & & \\
IT15 & 0,355 & 0,415 & 0,459 & 0,384 & 0,493 & 1 & & & \\
IT16 & 0,214 & 0,186 & 0,166 & 0,378 & 0,280 & $-0,023$ & 1 & & \\
IT17 & 0,222 & 0,358 & 0,523 & 0,381 & 0,378 & 0,493 & 0,147 & 1 & \\
IT18 & 0,186 & 0,150 & 0,235 & 0,459 & 0,249 & 0,094 & 0,503 & 0,384 & 1 \\
\hline
\end{tabular}


The items of the factor "connection" also demonstrate good results regarding their validity. Only item "IT20: I can understand and interpret the type of problem to be solved", shows a low correlation with the item "IT19: I can discover relationships between the use of computers and their impact on society", as illustrated in Table 9.

The factor "boldness" demonstrates a low correlation between its items. The items "IT27: When I find a very difficult problem, I have the courage to try to solve it" and "IT28: I am not afraid of failing" when compared to "IT23: I like to do things the way I want", even demonstrate a divergent correlation, indicating that they seem not to measure the same factor. "IT30: I am not ashamed to talk about my ideas", presents a moderate correlation only with item IT23, as illustrated in Table 10.

In general, the items of the factor "originality" show a moderate correlation. The item least correlated is "IT35: I think it is important to think about things in several different ways", demonstrating a moderate correlation only with the item "IT32: I try to solve a problem myself before asking someone", as shown in Table 11.

The factor "fluency" shows good results regarding its validity. Most of the item pairs have a moderate to high correlation, especially item "IT45: I have ideas for mobile applications that I could develop", demonstrating a high correlation with the items IT41, IT43, and IT44. Only item "IT41: I can write a computer program", does not have a significant correlation with the other items, as shown in Table 12.

The factor "flexibility" also demonstrates good results with all items having some moderate correlation. However, the item "IT49: I can find the materials I need to develop

Table 9

The correlation coefficient of connection

\begin{tabular}{lllll}
\hline & IT19 & IT20 & IT21 & IT22 \\
\hline IT19 & 1 & & & \\
IT20 & 0,233 & 1 & & \\
IT21 & 0,466 & 0,349 & 1 & 1 \\
IT22 & 0,412 & 0,591 & 0,498 & 1 \\
\hline
\end{tabular}

Table 10

The correlation coefficient of boldness

\begin{tabular}{lllllllll}
\hline & IT23 & IT24 & IT25 & IT26 & IT27 & IT28 & IT29 & IT30 \\
\hline IT23 & 1 & & & & & & & \\
IT24 & 0,191 & 1 & & & & & & \\
IT25 & 0,154 & 0,234 & 1 & & & & & \\
IT26 & 0,268 & 0,214 & 0,544 & 1 & & & \\
IT27 & $-0,074$ & 0,170 & 0,354 & 0,205 & 1 & & \\
IT28 & $-0,430$ & 0,211 & 0,408 & 0,210 & 0,521 & 1 & 1 \\
IT29 & 0,191 & 0,213 & 0,239 & 0,230 & 0,334 & 0,520 & 1 \\
IT30 & 0,333 & 0,205 & 0,090 & 0,227 & 0,137 & 0,042 & 0,056 & 1 \\
\hline
\end{tabular}


Table 11

The correlation coefficient of originality

\begin{tabular}{lllllllll}
\hline & IT31 & IT32 & IT33 & IT34 & IT35 & IT36 & IT37 & IT38 \\
\hline IT31 & 1 & & & & & & & \\
IT32 & 0,372 & 1 & & & & & & \\
IT33 & 0,719 & 0,378 & 1 & & & & & \\
IT34 & 0,464 & 0,204 & 0,373 & 1 & & & \\
IT35 & 0,172 & 0,398 & 0,212 & 0,126 & 1 & & \\
IT36 & 0,274 & 0,452 & 0,232 & 0,314 & 0,303 & 1 & 1 \\
IT37 & 0,603 & 0,144 & 0,605 & 0,462 & 0,013 & 0,313 & 1 \\
IT38 & 0,470 & 0,115 & 0,293 & 0,393 & 0,025 & 0,358 & 0,526 & 1 \\
\hline
\end{tabular}

Table 12

The correlation coefficient of fluency

\begin{tabular}{llllllll}
\hline & IT39 & IT40 & IT41 & IT42 & IT43 & IT44 & IT45 \\
\hline IT39 & 1 & & & & & & \\
IT40 & 0,342 & 1 & & & & & \\
IT41 & 0,259 & 0,267 & 1 & & & & \\
IT42 & 0,519 & 0,284 & 0,358 & 1 & & 1 & \\
IT43 & 0,376 & 0,389 & 0,396 & 0,493 & 1 & & \\
IT44 & 0,400 & 0,440 & 0,538 & 0,312 & 0,479 & 1 \\
IT45 & 0,412 & 0,393 & 0,557 & 0,344 & 0,515 & 0,755 & \\
\hline
\end{tabular}

Table 13

The correlation coefficient of flexibility

\begin{tabular}{llllll}
\hline & IT46 & IT47 & IT48 & IT49 & IT50 \\
\hline IT46 & 1 & & & & \\
IT47 & 0,454 & 1 & & & \\
IT48 & 0,424 & 0,210 & 1 & 1 & \\
IT49 & 0,297 & 0,396 & 0,014 & 0,401 & 1 \\
IT50 & 0,398 & 0,149 & 0,431 & \\
\hline
\end{tabular}

an idea", demonstrates a low correlation, almost zero, with the item "IT48: I like to work creating new things instead of doing repetitive exercises", as shown in Table 13.

The factor "elaboration" shows a moderate to a high correlation between its items. Item "IT51: I care about the details when I do something", is the one least correlated with the other items, as illustrated in Table 14.

In general, the analysis of most factors shows a moderate and high correlation between their items, such as the factors "originality" and "fluency", which indicates a good internal correlation. Only the factors "creative personality and curiosity", "knowledge and skills expansion" and "boldness" had items with divergent correlation. 
Table 14

The correlation coefficient of elaboration

\begin{tabular}{lllllll}
\hline & IT51 & IT52 & IT53 & IT54 & IT55 & IT56 \\
\hline IT51 & 1 & & & & & \\
IT52 & 0,183 & 1 & & & & \\
IT53 & 0,077 & 0,568 & 1 & & & \\
IT54 & 0,277 & 0,280 & 0,335 & 1 & & \\
IT55 & 0,453 & 0,360 & 0,271 & 0,504 & 1 & \\
IT56 & 0,035 & 0,383 & 0,494 & 0,330 & 0,302 & 1 \\
\hline
\end{tabular}

Yet, most items demonstrate a moderate to high correlation not only with the other items of the same factor but also with items of other factors. Examples include the item "IT12: With the knowledge I have, I am able to solve a new problem" or item "IT13: I like to participate in extracurricular activities to learn new things (field research, lectures, courses)", which are highly correlated with almost any other item. This also indicates the cohesion of the measurement instrument as a whole aiming at measuring ultimately one concept, creativity.

\subsubsection{How do the Underlying Factors Influence the Responses of the Items} of the Measuring Instrument?

A factor analysis was performed to confirm the number of factors that represent the 56 items of the instrument. To determine the number of factors to be retained in the factor analysis, the Cattell Scree Test was used, one of the most used techniques (Raîche et al., 2013). The test plots the factors in decreasing order in relation to the number of components. The interval between steep inclination and leveling, called "elbow", indicates the number of significant factors (Cattell, 1966). As illustrated in Fig. 2, the most

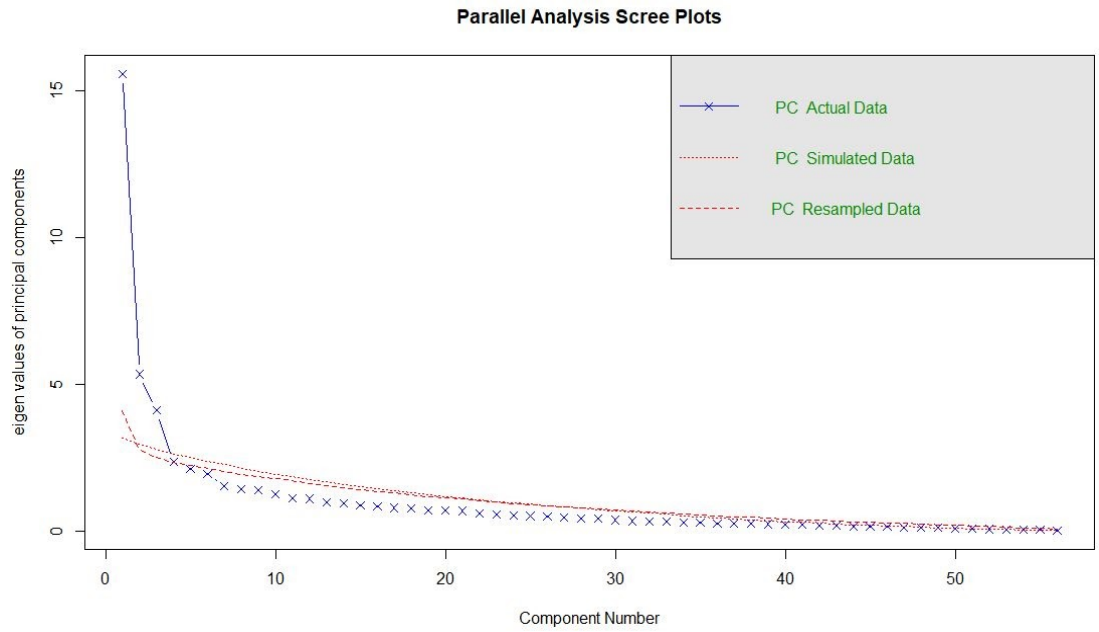

Fig. 2. Scree plot. 
significant change in the curve occurs between two and four factors, well below the 8 factors initially proposed. However, a sample of $n=76$ is still considered small for factor analysis with several factors (Comrey and Lee, 1992). Thus, taking into consideration that the first factor is well highlighted, showing a predominant dimension, we decided to perform a factor analysis with one factor.

According to Comrey \& Lee (1992), factor loading values from 0.3 are considered acceptable, values below the cutoff point may indicate that they are not measuring the factor and need to be revised. The greater the factor loading of an item, the more it will be correlated with the factor. In general, the items presented a good factor loading $>0.6$ for most items as presented in Table 15.

Table 15

Factor loadings with one factor

\begin{tabular}{|c|c|c|c|}
\hline Factor & Item & Item & F1 \\
\hline \multirow{9}{*}{$\begin{array}{l}\text { Creative } \\
\text { personality } \\
\text { and } \\
\text { curiosity }\end{array}$} & IT1 & $\begin{array}{l}\text { Sometimes I keep thinking about a problem a lot and keep trying to solve it, until } \\
\text { I find a solution, for example, doing a math exercise. }\end{array}$ & 0.671 \\
\hline & IT2 & I think it's important to have ideas. & 0.694 \\
\hline & IT3 & I have many useful ideas. & 0.541 \\
\hline & IT4 & I can do something fun with recycled material. & 0.602 \\
\hline & IT5 & I can think of new ways to help people. & 0.631 \\
\hline & IT6 & I like to do new things (visit new places, meet new people, etc.) & 0.512 \\
\hline & IT7 & I am a curious person about how things work. & 0.567 \\
\hline & IT8 & I can complete several things during the day. & 0.772 \\
\hline & IT9 & $\begin{array}{l}\text { I question beliefs, customs, and traditions, for example, not to go under the stairs } \\
\text { to avoid bad luck. }\end{array}$ & 0.261 \\
\hline \multirow{9}{*}{$\begin{array}{l}\text { Knowledge } \\
\text { and skills } \\
\text { expansion }\end{array}$} & IT10 & I like to learn new things. & 0.749 \\
\hline & IT11 & I am not afraid to learn new things. & 0.625 \\
\hline & IT12 & With the knowledge I have, I am able to solve a new problem. & 0.844 \\
\hline & IT13 & $\begin{array}{l}\text { I like to participate in extracurricular activities to learn new things (field research, } \\
\text { lectures, courses). }\end{array}$ & 0.838 \\
\hline & IT14 & I go online several times to learn new things. & 0.649 \\
\hline & IT15 & I like to discuss matters by giving my opinion. & 0.651 \\
\hline & IT16 & I know how to enjoy praise and criticism when redoing a school assignment. & 0.501 \\
\hline & IT17 & I can give constructive criticism. & 0.706 \\
\hline & IT18 & I learn from my mistakes. & 0.686 \\
\hline \multirow[t]{4}{*}{ Connection } & IT19 & $\begin{array}{l}\text { I can discover relationships between the use of computers and their impact on } \\
\text { society. }\end{array}$ & 0.827 \\
\hline & IT20 & $\begin{array}{l}\text { I can understand and interpret the type of problem to be solved, for example, how } \\
\text { to do a math exercise. }\end{array}$ & 0.763 \\
\hline & IT21 & I can pay attention to and understand other people's ideas. & 0.727 \\
\hline & IT22 & I can create new solutions by combining things I already know. & 0.771 \\
\hline \multirow[t]{4}{*}{ Boldness } & IT23 & I like to do things the way I want. & 0.299 \\
\hline & IT24 & I can do anything I want. & 0.338 \\
\hline & IT25 & I try to do what others think is impossible. & 0.621 \\
\hline & IT26 & My goals are always challenging. & 0.618 \\
\hline
\end{tabular}


Table 15 - continued from previous page

\begin{tabular}{|c|c|c|c|}
\hline Factor & Item & Item & F1 \\
\hline & IT27 & When I encounter a very difficult problem, I have the courage to try to solve it. & 0.687 \\
\hline & IT28 & I am not afraid of failing. & 0.409 \\
\hline & IT29 & I like to participate in challenges. & 0.502 \\
\hline & IT30 & I am not ashamed to talk about my ideas. & 0.295 \\
\hline \multirow[t]{8}{*}{ Originality } & IT31 & I like to create my own digital games. & 0.677 \\
\hline & IT32 & I try to solve a problem on my own before asking someone. & 0.605 \\
\hline & IT33 & I like to create new mobile apps and not just to use the ones that already exist. & 0.637 \\
\hline & IT34 & I already did something using the computer that I never thought was possible. & 0.621 \\
\hline & IT35 & I think it is important to think about things in many different ways. & 0.654 \\
\hline & IT36 & I imagine many things that do not yet exist. & 0.731 \\
\hline & IT37 & I like to modify computer programs from programs that other people have shared. & 0.738 \\
\hline & IT38 & I have ideas on how to make new games and how to improve them. & 0.720 \\
\hline \multirow[t]{7}{*}{ Fluency } & IT39 & $\begin{array}{l}\text { I can imagine different solutions to solve a problem (for example, how to get to } \\
\text { school faster). }\end{array}$ & 0.833 \\
\hline & IT40 & I find it easy to write a story for a game. & 0.558 \\
\hline & IT41 & I can write a computer program. & 0.663 \\
\hline & IT42 & $\begin{array}{l}\text { When I grow up, I would like to work with something that involves thinking about } \\
\text { several new ideas. }\end{array}$ & 0.754 \\
\hline & IT43 & I can think of a list of things that require little money but can improve my school. & 0.722 \\
\hline & IT44 & I am able to explain a computer program to colleagues. & 0.777 \\
\hline & IT45 & I have ideas for mobile apps that I could develop. & 0.712 \\
\hline \multirow[t]{5}{*}{ Flexibility } & IT46 & I am able to combine ideas in ways that other people have not tried. & 0.841 \\
\hline & IT47 & I can think of new ways to use a pan. & 0.664 \\
\hline & IT48 & I like to work on creating new things instead of doing repetitive exercises. & 0.676 \\
\hline & IT49 & I can find the materials I need to develop an idea. & 0.717 \\
\hline & IT50 & $\begin{array}{l}\text { If a certain resource is not available, I try to find a solution with other available } \\
\text { resources. }\end{array}$ & 0.803 \\
\hline \multirow[t]{6}{*}{ Elaboration } & IT51 & I care about the details when I do something. & 0.600 \\
\hline & IT52 & I pay attention to the colors and fonts used on the screen of a mobile application. & 0.637 \\
\hline & IT53 & After using an interesting mobile application, I like to talk to someone about it. & 0.744 \\
\hline & IT54 & When I'm interested in something, I pay attention to every detail. & 0.551 \\
\hline & IT55 & When I do homework, I like to make it beautiful and decorated. & 0.605 \\
\hline & IT56 & I like to make the screens of games or mobile applications that I create beautiful. & 0.674 \\
\hline
\end{tabular}

Only three items demonstrated a factor loading below 0.3 , indicating that these items could be excluded:

- IT9: I question beliefs, customs, and traditions, for example, not to go under the stairs so as not to be unlucky.

- IT23: I like to do things the way I want to.

- IT30: I am not ashamed to talk about my ideas.

Reconsidering their correspondence to the specific application domain, we, therefore, suggest to exclude them taking also in consideration the results of the correlation analysis. Item IT9 could be understood to be more related to critical thinking, rather than creativity. Item IT23 may not be formulated in a way that it is understood correctly, and 
may erroneously be interpreted as someone who is inconvenient and does only what s/ he wants. Item IT30 may also be more related to the trait of an outgoing personality than with "boldness" as part of the creativity trait.

\subsubsection{Discussion}

The results of the analysis show that, in addition to the exclusion of the three items identified in the factor analysis, no further reformulation of the questionnaire is necessary.

The correlation matrix indicates that most items have a moderate to high correlation, such as "fluency" and "elaboration", with almost all items showing a correlation above 0.29 . Only very few exceptions demonstrate even a divergent correlation, indicating that they do not measure the same factor. The item with the most divergent correlation is the "IT9: I question beliefs, customs, and traditions, for example, not to go under the stairs so as not to be unlucky" of the factor "creative personality and curiosity". Taking into consideration also its low factor loading below 0.3 , we suggest its exclusion from the questionnaire.

The factor "boldness" demonstrates various items with a correlation below 0.29 , also reflected through low factor loadings in the factor analysis with respect to "IT23: I like to do things the way I want to" and "IT30: I am not ashamed to talk about my ideas". Therefore, we also suggest the exclusion of these two items.

The factor analysis was performed with only one factor, due to the small sample size and the Scree Plot graph showing a predominant first factor. As a result, the SCORE model covers the most used factors in related assessment models, yet adding, unlike the other models, also items related to creativity in computing.

Despite a small sample, the analysis carried out indicates that the items, except the three items to be excluded, contribute to the measurement of the concept of creativity. Based on the results of the evaluation, we thus propose the exclusion of the three items resulting in a 53-items questionnaire.

\subsubsection{Threats to Validity}

Like any kind of research, this study's limitations may pose threats to its validity. Some threats are related to the design of the study. To mitigate this threat, we defined and documented a systematic research method. The SCORE model has been defined, decomposing the evaluation objective. The measuring instrument has been developed following scale and questionnaire development methods.

Another threat refers to the quality of the data pooled into a single sample, in terms of standardization of data (response format) and adequacy. As our study is limited exclusively to assessments that used the SCORE model, this risk is minimized as in all applications the same data collection instrument has been used. Another issue refers to the pooled data from different contexts. To mitigate this threat all case studies have been conducted in similar contexts.

A limitation of our study refers to the assessment of creativity. Adopting a nonexperimental research design (case study), only a post-test using self-assessment has been applied to evaluate the students' perceived skills. No pre-test has been applied and, therefore, it was not possible to accurately understand any skill differences promoted 
by computing education. However, regarding the self-assessment, although there is no consensus, there is evidence that self-assessment provides reliable, valid, and useful information for this type of study (Sitzmann et al., 2010), mainly when using a systematic, reliable, and valid assessment model.

A threat to external validity is related to the sample size and diversity of the data used for the evaluation. In respect to sample size, our evaluation used data collected from an application involving a population of 76 students from six different schools. In terms of statistical significance, this is a satisfactory sample size, allowing the generation of reasonable results (Wohlin et al., 2012).

In terms of reliability, a threat refers to what extent the data and the analysis are dependent on the specific researchers. To mitigate this threat, we systematically documented the evaluation of the SCORE model, clearly defining the study objective, the process of data collection, and the statistical methods used for data analysis. Another issue refers to the correct choice of statistical tests for data analysis. To minimize this threat, we performed a statistical evaluation following the guide for the construction of measurement scales as proposed by DeVellis (2016), which is aligned with procedures for the evaluation of internal consistency and construct validity of a measurement instrument (Trochim and Donnelly, 2018).

\section{Conclusions}

This article presents a model for the self-assessment of creativity in the context of computing education in K-12. Unlike other models, SCORE covers all factors defined by prominent frameworks also adding items related to computing proficiency concerning the specific context of computing education. The evaluation of the SCORE model, based on a total of 76 responses, indicates high internal reliability (Cronbach 's alpha $=0.961)$. Results regarding its validity also show that most items demonstrate a moderate to high correlation. Furthermore, the results of a factor analysis considering one single factor due to the small sample size, suggest the exclusion of three items, resulting in a 53-item questionnaire. We are currently planning to continue the evaluation in future case studies amplifying the application of the assessment model as we believe that SCORE is an important instrument to promote the development of creativity also in the Brazilian education context. To contribute in this respect, the instrument and analysis spreadsheet in English and Brazilian Portuguese are available online: https ://www . computacaonaescola.ufsc.br/en/score/.

\section{Acknowledgments}

We would like to thank all participants in the evaluation of the assessment model.

This work was supported by the CNPq (National Council for Scientific and Technological Development), a Brazilian government entity focused on scientific and technological development. 


\section{References}

Amabile, T.M. (1982). Social psychology of creativity: A Consensual Assessment Technique. Journal of Personality and Social Psychology, 43, 997-1013.

Auzmendi, E., Villa, A., Abedi, J. (1996). Reliability and Validity of a Newly Constructed Multiple-Choice Creativity Instrument. Creativity Research Journal, 9(1), 89-95.

Basili, V.R., Caldeira, G., Rombach, H.D. (1994). Goal Question Metric Paradigm. In: J. J. Marciniak, Encyclopedia of Software Engineering, Wiley-Interscience, New York.

Bennett, V.E., Koh, K.H, Repenning, A. (2013). Computing creativity: divergence in computational thinking. In: Proc. of the 44th ACM Technical Symposium on Computer Science Education. ACM, New York, NY, USA, 359-364.

Binkley, M., Ola, E., Herman, J. Raizen, S., Ripley, M., Rumble, M. (2011). Defining 21st-Century Skills. In: Assessment and Teaching of 21st-Century Skills. Springer, New York, 17-66.

Bolden, B., DeLuca, C., Kukkonen, T., Roy, S. Wearing, J. (2019). Assessment of Creativity in K-12 Education: A Scoping Review. Review of Education, 8(2), 343-376.

Brown, T. A. (2006). Confirmatory factor analysis for applied research. The Guilford Press, New York.

Budgen, D., Turner, M., Brereton, P., Kitchenham, B. (2008). Using mapping studies in Software Engineering. Evidence-based Software Engineering. Lancaster University, 195-204.

Cattell, R.B. (1966). The Scree Test for the Number of Factors. Multivariate Behavioral Research, 1(2), $245-276$.

Cohen, J. (1988). Statistical Power Analysis for the Behavioral Sciences. Routledge Academic, New York.

Comrey, A., Lee, H. (1992). A first course in factor analysis. Erlbaum, Hillsdale.

Cronbach, L.J. (1951). Coefficient alpha and the internal structure of tests. Psychometrika, 16, 297-334

CSTA. (2016). CSTA-12 Computer Science Framework. ACM, New York, NY, USA. http: //www.k12cs.org

Daniel, W. W. (1990). Spearman rank correlation coefficient. Applied Nonparametric Statistics. Boston: PWSKent, 358-365.

DeVellis, R.F. (2016). Scale Development: Theory and Applications. SAGE Publications, Beverly Hills.

Fields, Z., Bisschof, C. (2013). A Theoretical Model to Measure Creativity at a University, Journal of Social Sciences, 34(1), 47-59.

Grover, S., Pea, R. (2013). Computational Thinking in K-1: A review of the state of the field. Educational Researcher, 42(1), 38-43.

Gruszka, A., Tang, M. (2017). The 4P's creativity model and its application in different fields. In: M. Tang \& C. $\mathrm{H}$. Werner (Eds.), Handbook of the management of creativity and innovation: Theory and practice, World Scientific Publishing, Toh Tuck Link.

Guilford, J.P. (1950). Creativity. American Psychologist, 5, 444-454.

Guilford, J.P. (1956). The structure of intellect. Psychological Bulletin, 53(4), 267-293.

Guilford, J.P. (1967). Creativity: Yesterday, today and tomorrow. The Journal of Creative Behavior, 1, 3-14.

Hass, R.W., Burke, S. (2016). Implicit theories of creativity are differentially categorized by perspective and exemplar domain. Thinking Skills and Creativity, 19, 219-231.

Heintz, F., Mannila, L., Färnqvist, T. (2016). A review of models for introducing computational thinking, computer science and computing in K-12 education. In: Proc. of the Frontiers in Education Conference, Pennsylvania, USA, 1-9.

Hubwieser, P., Giannakos, M.N., Berges, M., Brinda, T., Diethelm, I., Magenheim, J., Pal, Y., Jackova, J., Jasute, E. (2015). A Global Snapshot of Computer Science Education in K-12 Schools. In: Proc. of the ITiCSE on Working Group Reports. ACM, New York, NY, USA, 65-83.

Kaufman, J.C. (2012). Counting the Muses: Development of the Kaufman Domains of Creativity Scale (KDOCS). Psychology of Aesthetics Creativity and the Arts, 6(4), 298-308.

Kaufman, J.C. (2019). Self-assessments of creativity: Not ideal, but better than you think. Psychology of Aesthetics, Creativity, and the Arts, 13(2), 187-192.

Kasunic, M. (2005). Designing an effective survey. Handbook CMU/SEI-2005-HB-004, Software Engineering Institute. Carnegie Mellon University, Pittsburgh.

Losby, J., Wetmore, A. (2012). Likert Scales - Odd or Even? http://aea365.org/blog/jan-losby-and-anne-wetmore-likert-scales-odd-or-even/

Matlin, M.W. (2014). Cognitive Psychology, 5th ed., John Wiley, New Jersey.

Manske, S., Hoppe, H.U. (2014). Automated indicators to assess the creativity of solutions to programming exercises. In: Proc. of the IEEE 14th International Conference on Advanced Learning Technologies, Athens, Greece, 497-501. 
McKlin, T., Magerko, B., Lee, T., Wanzer, D., Edwards, D., Freeman, J. (2018). Authenticity and Personal Creativity: How EarSketch Affects Student Persistence. In: Proc. of the 49th ACM Technical Symposium on Computer Science Education, ACM, New York, NY, USA, 987-992.

Mellini, B., Talamo, A., Giorgi, S. (2010). Psycho-Pedagogical Framework for Fostering Creativity. Project report, EU project.

Martins-Pacheco, L.H., Degering, L., Mioto, F., Grease von Wangenheim, C., Borgato, A.F., Petri, G. (2020). Improvements in bASES21: 21st-Century Skills Assessment Model to K12. In: Proc. of the 12th International Conference on Computer Supported Education, 297-307.

Nakano, T.C. (2020). Métodos Atuais para Avaliação da Criatividade: Vantagens e Questionamentos. Avaliação Psicológica, 19(1), 97-105.

Oihus, P., Surovek, A., Jensen P. (2013). Design Wars: Developing student creativity through competition. In: Proc. of the IEEE Frontiers in Education Conference, Oklahoma City, OK, USA, 137-139.

P21. (2020). 21st-Century Skills. http://www . p21.org

Petersen, K., Feldt, R., Mujtaba, S., Mattsson, M. (2008). Systematic mapping studies in software engineering. In: Proc. of the 12th Int. Conference on Evaluation and Assessment in Software Engineering. BCS Learning \& Development Ltd., Swindon, GBR, 68-77.

Petty, G. (1997). How to be better at creativity. Kogan Page Limited, London.

Raîche, G., Walls, T.A., Magis, D., Riopel, M., Blais, J-G. (2013). Non-Graphical Solutions for Cattell's Scree Test. Methodology, 9(1), 23-29.

Rahimi, H., Arbabisarjou, A., Allammeh, S.M., Aghababaei, R. (2011). Relationship between Knowledge Management Process and Creativity among Faculty Members in the University. Interdisciplinary Journal of Information, Knowledge, and Management, 6, 017-033.

Rhodes, M. (1961). An analysis of creativity. The Phi Delta Kappan, 42, 305-310.

Romero, M., Lepage, A., Lille, B. (2017). Computational thinking development through creative programming in higher education. International Journal of Educational Technology in Higher Education, 14, 1-15.

Ross, J.A. (2006). The reliability, validity, and utility of self-assessment. Practical Assessment, Research \& Evaluation, 11(10), 1-13.

Runco, M.A., Acar, S. (2012). Divergent Thinking as an Indicator of Creative Potential. Creativity Research Journal, 24(1), 66-75.

Runco, M.A., Plucker J.A., Lim W. (2001). Development and Psychometric Integrity of a Measure of Ideational Behavior. Creativity Research Journal, 13(3-4), 393-400.

Said-Metwaly, S., Noortgate, W., Kyndt, E. (2017). Approaches to Measuring Creativity: A Systematic Literature Review, Creativity. Theories - Research-Applications, 4(2), 238-275.

Scherer, R., Siddiq, F., Viveros, B.S. (2019). The Cognitive Benefits of Learning Computer Programming: A Meta-Analysis of Transfer Effects. Journal of Educational Psychology, 111(5), 764-792.

Shell, D.F. Hazley, M.P., Soh, L., Ingraham, E., Ramsay, S. (2013). Associations of students' creativity, motivation, and self-regulation with learning and achievement in college computer science courses. In: Proc. of the IEEE Frontiers in Education Conference, Oklahoma City, OK, USA, 1637-1643.

Sitzmann, T., Ely, K., Brown, K.G., Bauer, K.N. (2010). Self-Assessment of Knowledge: A Cognitive Learning or Affective Measure? Academy of Management Learning \& Education, 9(2), 169-191.

Snyder, H.T., Hammond, J.A., Grohman, M.G., Katz-Buonincontro, J. (2019). Creativity measurement in undergraduate students from 1984-2013: A systematic review. Psychology of Aesthetics, Creativity, and the Arts, 13(2), 133-143.

Soroa G. Balluerka, N., Hommel, B., Aritzeta, A. (2015). Assessing interactions between cognition, emotion, and motivation in creativity: The construction and validation of EDICOS. 2015. Thinking Skills and Creativity, 17, 45-58.

Sternberg, R. (1985). Implicit Theories of Intelligence, Creativity, and Wisdom. Journal of Personality and Social Psychology, 49, 607-627.

Susnea, I., Vasiliu, G. (2016). A Fuzzy Logic Software Tool and a New Scale for the Assessment of Creativity. International Journal of Computers Communications \& Control, 11(3), 441-449.

Torrance, E.P. (1966). The Torrance Tests of Creative Thinking. Personnel Press, Princeton.

Torrance, E.P. Goff, K. (1989). A quiet revolution. Journal of Creative Behavior, 23(2), 136-145.

Trochim, W.M., Donnelly, J.P. (2018). Research Methods Knowledge Base. Atomic Dog Publishing, Mason.

Voogt, J., Roblin, N.P. (2012). A comparative analysis of international frameworks for 21 st-century competencies: Implications for national curriculum policies. Journal of Curriculum Studies, 44(3), 299-321.

Walia, C. (2019). A Dynamic Definition of Creativity. Creativity Research Journal, 31(3), 237-247.

Webb, M., Davis, N., Bell, T., Katz, Y.J., Reynolds, N., Chambers, D.P., Sysło, M.M. (2017). Computer science in K-12 school curricula of the 21st century: Why, what and when?. Education and Information Technologies, 22, 445-468. 
Wohlin, C., Runeson, P., Host, M., Ohlsson, M.C., Regnell, B., Wesslen, A. (2012). Experimentation in Software Engineering: An Introduction. Springer, Berlin.

Yadav, A., Cooper, S. (2017). Fostering Creativity Through Computing. Communications of the ACM, 60(2), 31-33.

Yin, R.K. (2009). Case study research: design and methods, 4th. ed., Sage Publications, Beverly Hills.

G. Lehmkuhl is a student of the undergraduate course on Information Systems at the Federal University of Santa Catarina (UFSC), Florianópolis, Brazil, and a research student at the initiative Computing at Schools/INCoD/INE/UFSC. She received her BSc in 2020 from the Federal University of Santa Catarina. Her main research interests are in the area of computing education and assessment.

C. Gresse von Wangenheim is a professor at the Department of Informatics and Statistics (INE) of the Federal University of Santa Catarina (UFSC), Florianópolis, Brazil, where she coordinates the Software Quality Group (GQS) focusing on scientific research, development and transfer of software engineering models, methods and tools and software engineering education. She also coordinates the initiative Computing at Schools, which aims at bringing computing education to schools in Brazil. She received the Dipl.-Inform. and Dr. rer. nat. degrees in Computer Science from the Technical University of Kaiserslautern (Germany), and the Dr. Eng. degree in Production Engineering from the Federal University of Santa Catarina.

L. H. Martins-Pacheco is a professor at the Department of Informatics and Statistics (INE) of the Federal University of Santa Catarina (UFSC), Florianópolis, Brazil. She received the degree Dr. Eng. degree in Production Engineering from the Federal University of Santa Catarina (2002). She has bachelor's degrees in Electrical Engineering (1983) and in Psychology (2010) from the Federal University of Santa Catarina. She had some administrative positions in university as head of Department of Informatics and Statistics (INE) and vice-rector. She is interested in computers in education and computers and society.

A. F. Borgatto is a professor at the Department of Informatics and Statistics (INE) of the Federal University of Santa Catarina (UFSC). His main research interest focuses on the Item Response Theory applied in the area of education.

N. da Cruz Alves is a Ph.D. student at the Graduate Program in Computer Science (PPGCC) at the Federal University of Santa Catarina (UFSC), Florianópolis, Brazil, and a research student at the initiative Computing at Schools/INCoD/INE/UFSC. She received her BSc (2017) and MSc (2019) in Computer Science from the Federal University of Santa Catarina. Her main research interests are computing education, creativity, and assessment. 